\title{
Ensino Superior a Distância: \\ Metodologias ativas com uso de tecnologias digitais
}

\author{
Rosimeire Aparecida Soares Borges ${ }^{1}$ \\ Ana Elisa Cunha Anderi Castilho² \\ Márcia Aparecida Caetano Sassaki ${ }^{3}$ \\ Stanley Santos e Vitor ${ }^{4}$ \\ Luiz Claudio Dala Rosa Junior ${ }^{5}$
}

\section{RESUMO}

Este estudo aborda as tecnologias digitais em metodologias ativas no Ensino Superior, em cursos de graduação a distância, e discute práticas educacionais mais inovadoras para esses cursos. Para isso, foi feito um estudo bibliográfico em três etapas: definição do objetivo, pesquisa de estudos correlatos e seleção daqueles passíveis de análise. Os resultados obtidos em uma busca no Google acadêmico foram filtrados a partir da leitura dos títulos, resumos e textos, considerando os publicados entre 2014 e 2019. As conclusões mostraram que essas tecnologias oportunizam o uso didático de metodologias ativas em cursos de graduação a distância e podem auxiliar na aprendizagem e no desenvolvimento de habilidades, como o poder de análise, comunicação e argumentação dos alunos. Para que se concretizem esses usos, existe a necessidade de reestruturação curricular desses cursos e de formação docente com competências para gerir essas metodologias com ferramentas tecnológicas.

Palavras-chave: Tecnologias digitais. Metodologias Ativas. Ensino Superior EaD.

\footnotetext{
${ }^{1}$ rasborges3@gmail.com - Universidade do Vale do Sapucaí

2 anaelisa.anderi@gmail.com - Universidade do Vale do Sapucaí

3 caetanosassaki@gmail.com - Universidade do Vale do Sapucaí

${ }^{4}$ stanleymestrado@gmail.com - Universidade do Vale do Sapucaí

${ }^{5}$ adm@redesac.com.br - Universidade do Vale do Sapucaí
} 


\section{Distance Learning Higher Education: active methodologies using digital technologies}

\section{ABSTRACT}

This study addresses digital technologies in active methodologies in distance learning higher education courses and discusses more innovative educational practices for them. A bibliographic study was made in three steps: define the goal, search correlated studies, and select the ones for analysis. A Google Scholar search had its results filtered by reading the titles, the abstracts, and the full text, considering the ones published from 2014 to 2019. The results showed that these technologies enable the didactic use of active methodologies in distance learning higher education courses and can assist students' learning and the development of skills such as the power of analysis, communication, and argumentation. To materialize the use of active methodologies with digital technologies in these distance education courses, curricular restructuring of these courses and teacher training in skills to manage these methodologies with technological tools is needed.

Keywords: Digital technologies. Active Methodologies. Distance Learning Higher Education. 
$\mathrm{Na}$ contemporaneidade, a sociedade vivencia grandes mudanças que se tornam constantes em relação aos desafios causados pelo advento das Tecnologias Digitais da Informação e Comunicação (TDIC), o que reflete diretamente no processo educativo. Isso, porque, com o passar dos anos, a educação encontra dificuldades para acompanhar as transformações provocadas por essas tecnologias que vieram para afetar e criar modos diferenciados de agir, pensar e aprender, gerando inúmeros e grandes desafios na educação (LÁZARO; SATO; TEZANI, 2018).

As tecnologias digitais podem auxiliar os processos de ensino e aprendizagem em diferentes cenários da educação, ampliando o "modo de agir e produzir conhecimento" (FERRARINI; SAHEB; TORRES, 2019). Na Educação a Distância (EaD), não é diferente. A evolução das TDICs intensificou a presença da EaD no Brasil e, dessa maneira, segundo Souza e Morales (2018), nos últimos anos, tem se reafirmado como uma das possibilidades de ampliar o número de vagas no Ensino Superior que abrange os cursos de graduação e de pósgraduação (BRASIL, 1996).

Nesse nível de ensino, com a evolução das TDICs, a EaD imprimiu novas possibilidades nos processos educativos no tocante ao tempo e ao espaço. Estão sendo propiciadas emergentes formas de interação e comunicação entre as pessoas, modificando o conceito de relações sociais e humanas, o que tem sido um convite para se repensar as metodologias de ensino e práticas pedagógicas até então utilizadas. Assim, vêm ganhando força as metodologias centradas nos estudantes e que preveem atividades colaborativas, nas quais os docentes agem como mediadores. A construção do conhecimento vai além das fronteiras estabelecidas pelas disciplinas, impulsionadas pelas novas formas de interação e de produção compartilhada de conhecimento (ALMEIDA; TELES, 2018).

Corroborando o exposto, Valente (2014, p. 83) afirma que as TDICs oferecem meios e condições que alteram diversas características da $\mathrm{EaD}$, "como as concepções teóricas, as abordagens pedagógicas, as finalidades da EaD e os processos de avaliação da aprendizagem dos alunos". Essas tecnologias favorecem o andamento das aulas e, segundo Silva e Lima (2019, p. 41), fornecem subsídios para a potencialização da aprendizagem dos estudantes, ampliando "o conhecimento, o saber, as competências e habilidades múltiplas para a formação profissional" e podem ser integradas às metodologias ativas. De acordo com Moran (2018, p. 4), são denominadas como metodologias ativas aquelas que "dão ênfase ao papel protagonista do aluno, ao seu envolvimento direto, participativo e reflexivo em todas as etapas do processo, experimentando, desenhando, criando [...]". Para Masetto (2018, p. 653), as metodologias ativas são "estratégias que pretendem incentivar e desenvolver o protagonismo e a autonomia do aluno em seu processo de aprendizagem e formação profissional."

No Ensino Superior, as metodologias ativas subsidiadas pelo uso das TDICs, conforme Souza e Morales (2015), podem proporcionar aulas mais interessantes, de modo a formar futuros profissionais preparados para o trabalho na sociedade atual, que dispõe de redes de comunicação possibilitadas por essas tecnologias. Valente $(2019$, p. 99) observa que essas 
metodologias "estão sendo gradativamente implantadas em alguns cursos do Ensino Superior justamente para colocar esse aluno na situação de protagonista da sua aprendizagem". Sendo assim, no contexto educacional, desponta um novo formato de educação que possibilita a elaboração das atividades pelos alunos, bem como a entrega de trabalhos e até mesmo o processo de avaliação. Nesse cenário, novos conhecimentos e atitudes são exigidos dos docentes, pois há a necessidade de inovação das práticas pedagógicas, e exige-se dos alunos que sejam agentes do processo de aprendizagem, desenvolvendo a autoaprendizagem e a autonomia (SILVA; LIMA, 2019).

Para Lázaro, Sato e Tezani (2018), o mundo virtual e o envolvimento da linguagem digital oferecidos pelas TDICs admitem a combinação de mídias diferenciadas, como imagem e som em equipamentos ligados à rede internet - computadores, celulares, smartphones, tablets, dentre outros. Essa situação mostra um panorama educacional com necessidade de transformação, em que as universidades privadas e públicas estão buscando a institucionalização da EaD e adotando novos paradigmas. Costa (2012, p. 29) refere-se ao processo de institucionalização da EaD no Brasil, mencionando que esse movimento se deu desde os primórdios da era digital e que passou por sua oficialização no âmbito de reformas educacionais na "década de 1970 do século XX, até alcançar sua institucionalização, no Sistema Educacional Brasileiro, por intermédio da LDB 9.394/1996”. Para essa autora, o fato de a EaD ter sido acionada para integrar o Sistema Educacional Brasileiro se deve por "proporcionar diferentes modos de organização, de combinação de vários recursos. Sobretudo, através de um conjunto de ações envolvendo o emprego das tecnologias" (COSTA, 2012, p. 136).

Assim, no contexto do Ensino Superior, especificamente dos cursos de graduação em EaD, as TDICs podem beneficiar um exercício educativo que considere a necessidade de reconfiguração "do modo de ver, conhecer e atuar sobre os contextos práticos da profissão, seja nas questões estruturais seja nas pedagógicas e didáticas" (NONATO; SALES; SARLY, 2019, p. 163). Segundo evidenciam esses autores, ao integrar as metodologias ativas com as TDICs, vislumbram-se práticas pedagógicas inovadoras que viabilizam o andamento desses cursos, haja vista que tais metodologias apontam para possibilidades de "práticas comunicacionais, informacionais e político-sociais de formação" em que essas tecnologias possam contribuir "para a visualização e o exercício formativo de vivências necessárias e exigências de um profissional do século XXI" (NONATO; SALES; SARLY, 2019, p. 163).

Neste artigo, foi considerada uma abordagem do uso das TDICs em metodologias ativas em cursos de graduação em EaD, com o objetivo de discutir sobre essas metodologias em práticas educacionais integradas às TDICs e que são possíveis de serem realizadas nesses cursos. Estudos como o de Moran (2015; 2018), Santo e Colvara (2019) e Valente (2014) dialogam sobre as metodologias ativas como aquelas que possibilitam práticas pedagógicas inovadoras, nas quais os estudantes podem ser protagonistas e os docentes atuam como moderadores e orientadores para que ocorra a aprendizagem. Para Nonato, Sales e Sarly (2019), esses métodos são promissores nesse nível de ensino por propiciar ao estudante "práticas curiosas, investigativas, desafiadoras que apreendam o desejo por estudar" e estar sempre em contato com colegas e professores no processo educativo.

Em cursos de graduação, realizados na modalidade EaD, esse contato é estabelecido por meio de várias atividades que são realizadas on-line e subsidiadas pelas TDICs em 
Ambientes Virtuais de Aprendizagem (AVA). Trata-se de ambientes em que as atividades podem ser realizadas de forma colaborativa, promovendo o desenvolvimento dos estudantes na direção de uma aprendizagem com significado (DONATO; GHILARDI, 2018). Conforme evidenciam Oliveira, Cunha e Nakayama (2016), nesses espaços podem ocorrer a interação entre alunos e professores, de forma síncrona e assíncrona ${ }^{6}$, pois possuem dispositivos que permitem a comunicação e a aplicação de diferentes estratégias para a participação ativa desses atores do processo de educar, bem como o compartilhamento de materiais, o envio e devolução de atividades etc.

Nesse panorama, a inovação de cursos de graduação a distância vai em direção de compreender de maneira mais abrangente os processos de ensino e de aprendizagem, como também valorizar os alunos como sujeitos desses processos, incentivando-os para o desenvolvimento da autonomia e criticidade frente às transformações dos diferentes ambientes e ambiências existentes e das maneiras de comunicação e de interação.

\section{EDUCAÇÃO SUPERIOR A DISTÂNCIA E TECNOLOGIAS DIGITAIS}

Nos últimos anos do século XX, foram divulgadas várias normativas com o objetivo de regulamentar a EaD. Com a aprovação da Portaria $n^{\circ} 2.253$, de 18 de outubro de 2001 (BRASIL, 2001), a possibilidade de oferta de $20 \%$ das disciplinas na modalidade semipresencial nos cursos regulares das IES foi oficializada. No entanto, a Portaria Ministerial $n^{\circ} 4059$, de 10 de dezembro de 2004 , em seu Art. $1^{\circ}$, inciso II, determina o limite de $20 \%$ da grade curricular dos cursos superiores presenciais, para a oferta de disciplinas na modalidade a distância (BRASIL, 2004).

A presença das TDICs facilita o acesso das pessoas à educação e influencia as normativas que regulamentam o Ensino Superior na modalidade presencial. As Instituições de Ensino Superior (IES) pertencentes ao Sistema Federal de Ensino foram autorizadas, por meio da Portaria ${ }^{\circ} 2.117$, de 06 de dezembro de 2019 (BRASIL, 2019), em seu Art. $1^{\circ}$, a ofertar cursos de graduação presenciais com carga horária na modalidade EaD, observando a legislação educacional vigente. Essa permissão amplia a carga horária anterior permitida e passa de $20 \%$ para $40 \%$ da carga horária total do curso em sua organização pedagógica e curricular. Esse aumento em cursos presenciais pode indicar que o advento das tecnologias veio para trazer flexibilidade na Educação Superior.

Em relação aos cursos superiores oferecidos na modalidade EaD, as TDICs vieram proporcionar a interação síncrona e assíncrona dos atores envolvidos nos processos de ensino e aprendizagem em tempos e espaços diversificados. Regulamentando o Art. 80 da Lei 9.394/1996, o Decreto $n^{\circ}$ 9.057, de 25 de maio de 2017, em seu Art. $1^{\circ}$, define a EaD nos seguintes termos:

a modalidade educacional na qual a mediação didático pedagógica nos processos de ensino e aprendizagem ocorra com a utilização de meios e

\footnotetext{
${ }^{6}$ Nos Referenciais de Qualidade para Educação Superior a Distância (BRASIL, 2007) consta que a instituição de Ensino Superior em seus cursos deverá "valer-se de modalidades comunicacionais síncronas e assíncronas como videoconferências, chats na internet, fax, telefones, para promover a interação em tempo real entre docentes, tutores e estudantes" (BRASIL, 2007, p.12).
} 
tecnologias de informação e comunicação, com pessoal qualificado, com políticas de acesso, com acompanhamento e avaliação compatíveis, entre outros, e desenvolva atividades educativas por estudantes e profissionais da educação que estejam em lugares e tempos diversos (BRASIL, 2017).

Ainda sobre a EaD, o Art. $2^{\circ}$ do Decreto $n^{\circ}$ 9.057/17 determina que o Ensino Superior pode ser ofertado "na modalidade a distância nos termos deste decreto, observadas as condições de acessibilidade que devem ser asseguradas nos espaços e meios utilizados" e no tocante às atividades realizadas presencialmente nesses cursos superiores oferecidos on-line, o Art. $4^{\circ}$ da Lei ${ }^{\circ} 9.057 / 2017$ estabelece que:

As atividades presenciais, como tutoriais, avaliações, estágios, práticas profissionais e de laboratório e defesa de trabalhos, previstas nos projetos pedagógicos ou de desenvolvimento da instituição de ensino e do curso, serão realizadas na sede da instituição de ensino, nos polos de educação a distância ou em ambiente profissional, conforme as Diretrizes Curriculares Nacionais (BRASIL, 2017).

No que se refere às atividades realizadas a distância, as TDICs são fundamentais, pois, segundo Bacich e Moran (2018, p. 4), essas tecnologias são ferramentas que já fazem parte do cotidiano e promovem uma pluralidade das interações, tornando-se auxiliares no processo educacional tanto para o professor quanto para os estudantes. Gomes (2013, p. 18), corrobora ao mencionar que "não se pode negar que os meios digitais potencializam essas e outras formas de trabalho pedagógico". No entanto, esse autor adverte que é preciso que a Educação a Distância deixe de ser tratada somente como uma modalidade de ensino e uma oportunidade de acesso à universidade, pois os meios digitais mostram uma tendência de novas "formas de relacionamento interpessoal, de ampliação dos sentidos do tempo e do espaço, para outras relações de trabalho e para a conectividade ininterrupta" (GOMES, 2013, p. 22).

Valente (2014) explana que as tecnologias digitais empregadas no Ensino Superior a distância permitem o acompanhamento dos alunos em ambientes virtuais, por meio dos quais são compartilhadas as atividades, os materiais didáticos e de suporte para a realização de trabalhos, além de possibilitar a interação entre professores, tutores e alunos, bem como servir de plataforma para os alunos enviarem seus trabalhos e realizarem as avaliações. Desse modo, as ferramentas digitais possibilitam o "monitoramento das dificuldades mais previsíveis" dos estudantes, e, posteriormente, preveem a ampliação da problematização e dos significados na elaboração das sínteses, sendo que as TDICs viabilizam a realização de uma educação mais personalizada (YAEGASHI et al., 2017).

Tal cenário exige do professor uma formação profissional e planejamento diante das mudanças profundas as quais desafiam o papel da docência universitária, pois o docente necessita ser um mediador pedagógico no processo de construção do conhecimento do aluno e suas práticas pedagógicas precisam ir além do espaço da sala de aula e, portanto, ser realizada em diferentes ambientes, como os virtuais, presenciais e profissionais (MASETTO, 2018). Isso mostra os reflexos da sociedade atual em que se constituem, mais e mais, práticas culturais com base nas TDIC, havendo um campo promissor que impõe refletir sobre os elementos que têm subsidiado a "cultura digital" e pensar nas formações que se pautam em 
relações e práticas com essas tecnologias, ou seja, formações típicas dessa cultura (ALONSO; SILVA, 2018, p. 508).

Ainda, de acordo com Masetto (2018), essa nova realidade exige que o professor universitário abdique do velho conceito de ensino e de metodologias ultrapassadas e passe a explorar o uso das TDIC em diferentes métodos de ensino, com possibilidades em que o novo não gere mais medo. A formação docente passa, assim, a envolver questões sociais, éticas e de cunho profissional para que possa, junto a seus alunos, conduzir os processos de ensino e de aprendizagem na construção desse novo modelo ou sistema de ensino com metodologias que envolvam atividades com a participação dos alunos em prol de uma formação que visa à autonomia e à cidadania.

\section{METODOLOGIAS ATIVAS}

No dizer de Moran (2018, p. 4), as metodologias ativas são concebidas como "[...] diretrizes que orientam os processos de ensino e aprendizagem, que se concretizam em estratégias, abordagens e técnicas concretas, específicas e diferenciadas". Para Ferrarini, Saheb e Torres (2019), ao longo da história na área educacional, várias metodologias de ensino vêm sendo construídas, cada uma com suas características específicas do seu tempo, e que acabam por influenciar as práticas educacionais. Evidenciam-se na atualidade uma série de metodologias ativas que se tornaram diferentes por suas técnicas, estratégias e abordagens, determinando o papel do professor e do aluno no processo de ensino e aprendizagem. Para Lázaro, Sato e Tezani (2018, p. 2), aos professores universitários cabe:

[...] embasar de modo teórico e prático a formação dos futuros profissionais, levando em consideração as mudanças sociais e tecnológicas, para que este atue em múltiplas frentes e abordem atividades que contemplem o aluno como sujeito ativo da construção do conhecimento, capaz de pesquisar, selecionar e interpretar as diversas informações, bem como compartilhar saberes entre os seus pares.

Há muitas características que evidenciam as metodologias ativas, dentre as quais podese citar: a autonomia, o protagonismo dos alunos e a flexibilidade dos acessos virtuais, estes que podem ser individuais ou até mesmo em grupos, apoiados pelas tecnologias (SANTO; COLVARA, 2019; VALENTE, 2014). Conforme Valente (2014, p. 145), as TDICs "podem estar interligadas em rede e, por sua vez, interligadas à internet, constituindo-se em um dos mais poderosos meios de troca de informação e de realização de ações cooperativas". Lázaro, Sato e Tezani (2018) afirmam que a internet permite aos usuários realizarem cursos e pesquisas, consultar diversas fontes de informações, comunicar-se com diferentes pessoas, não existindo barreiras de tempo e de espaço, e ainda realizar publicações em diversos canais. No entanto, Camargo, Lima e Torini (2019, p. 113) chamam a atenção para o descompasso existente entre o reconhecimento da influência da internet na formação dos estudantes - com grandes expectativas em razão do potencial das TDICs - e os "letramentos parciais, marcados pela ênfase nos aspectos técnicos e com pouca consistência nos usos avançados das tecnologias, tanto por parte dos docentes quanto dos estudantes".

O que se pode dizer é que, quando utilizada com a criticidade das informações, a internet possibilita ações de mediação docente na promoção de um processo educativo 
dinâmico e colaborativo, o que pode beneficiar o desenvolvimento dos estudantes. Nesse sentido, Masetto (2018, p. 662) delineia o papel do professor:

Um professor que sem deixar de lado seus conhecimentos, suas pesquisas, sua experiência profissional descobre seu novo papel de mediador pedagógico e de parceiro do aluno na construção da aprendizagem e da formação profissional. Um professor que se coloca como um facilitador, incentivador ou motivador da aprendizagem; que ativamente colabora para que o aprendiz chegue aos objetivos de sua formação profissional; que manifesta disponibilidade para colaborar na superação das dificuldades do aluno; que coloca o aprendiz frente a frente com questões éticas, sociais, profissionais.

As metodologias ativas, segundo Moran (2015), devem estar alinhadas aos objetivos do ensino, de modo a estimular os alunos a serem proativos na realização das atividades, com criatividade, sempre aumentando o nível de complexidade, tornando-os cada vez mais curiosos, autônomos e protagonistas na construção do conhecimento. Diante disso, o uso dessas metodologias para a realização de atividades que venham a contribuir para a inovação dos processos de ensino e aprendizagem pode promover a interação entre os atores do processo educativo, em diferentes espaços e de formas diversificadas.

Como estratégia principal, as metodologias ativas visam à problematização para motivar os alunos que, mesmo sendo confrontados com determinado problema, conseguem relacioná-lo com o contexto, de modo a atribuir significado às próprias descobertas. Assim, como características, as metodologias ativas podem derrubar barreiras em relação à questão de espaço e tempo, pois as TDIC possibilitam executar as tarefas de forma autônoma por parte dos alunos, o que é esperado para que façam atividades virtuais individuais ou outros tipos de trabalhos em ambiente virtuais para testes, experimentos e simulações (SANTO; COLVARA, 2019). Para esses autores,

[...] as metodologias ativas se baseiam em formas de desenvolver 0 processo de aprender, utilizando experiências reais ou simuladas, visando às condições de solucionar, com sucesso, desafios advindos das atividades essenciais da prática social em diferentes contextos (SANTO, COLVARA, 2019, p. 5).

As metodologias ativas disponíveis no processo educacional destacam-se pela sua eficácia e pela facilidade de aplicação. O ensino híbrido, por exemplo, é um formato de educação que tem como pressuposto as diferenciadas formas de ensino e aprendizagem, os diferentes tipos de interação e os diversificados ambientes. Na atualidade, as plataformas educacionais virtuais têm evoluído muito com os investimentos das universidades, tornando possível essa relação do aprender com o uso tecnológico das metodologias ativas, porém muitos educadores não estão preparados para essas mudanças e para a nova realidade na qual precisam conciliar uma gama de ferramentas e metodologias de ensino ao utilizar tais recursos (LÁZARO; SATO; TEZANI, 2018).

Valente (2014) menciona que a utilização das TDICs estimulou as transformações da EaD, que até o final da década de 1980 era realizada por meio de material impresso, este separado de forma organizada, entregue ao estudante e colocado em uso a partir da disponibilidade de tempo e local de estudo. Caracterizava-se, assim, em um ensino feito a distância, deixando clara a divisão espacial e temporal entre os docentes e os estudantes 
(VALENTE, 2014). De modo mais específico, Maia e Mattar (2007) afirmam existir três gerações da EaD, sendo a primeira a dos "cursos por correspondência" que emergiu em meados do século XIX, direcionados à formação por meio de materiais enviados aos estudantes pelos correios. A segunda geração da EaD, denominada "novas mídias e universidade abertas", já contou com tecnologias em meios de comunicação, como o rádio, a televisão, o telefone e materiais como as fitas de áudio/vídeo, e, em 1969, com a evolução da EaD, registra-se a criação das universidades abertas de ensino a distância. A terceira geração, "EaD on-line", é considerada como a que admite novas visões do sistema educacional, com o uso das tecnologias digitais que ganharam força no ano de 1995 com o início da internet e a possibilidade colocada pelos AVAs. Dessa maneira, o novo formato de EaD, com base no uso das redes, propõe que ocorram mudanças no processo educativo dessa modalidade de educação, haja vista que propiciam novas formas de interação, comunicação e participação dos estudantes na própria formação.

No entanto, Valente (2014) considera que a educação está em um nível de transição, no qual coabitam atividades conservadoras de ensino EaD baseadas em materiais impressos ou em suportes tecnológicos, como CD, rádio e TV; exercícios de EaD executados com o auxílio das TDICs a partir do uso de AVA e metodologias ativas centradas em atividades de e-learning realizadas a distância, que consistem em uma abordagem educacional utilizada tanto na EaD quanto para complementar as atividades educacionais presenciais que exigem a utilização de pesquisas. As propostas de e-learning podem auxiliar na interação e colaboração entre alunos e professores e "facilitar o acesso à informação ou até mesmo o uso das TDIC no desenvolvimento de projetos ou atividades curriculares cumpridas presencialmente" (VALENTE, 2014, p. 84). Portanto, podem viabilizar a comunicação entre o docente e os estudantes, facilitando o acesso à informação e o uso das TDICs em projetos ou trabalhos.

Nesse contexto, as interações entre professor e alunos ocorrem no modo digital, por meio das tecnologias móveis, mantendo interação com todos e com cada um ao mesmo tempo. Bacich e Moran (2015, p. 1) afirmam que "a educação sempre foi misturada, híbrida, sempre combinou vários espaços, tempos, atividades, metodologias, públicos. Agora esse processo, com a mobilidade e a conectividade, é muito mais perceptível, amplo e profundo: trata-se de um ecossistema mais aberto e criativo". Nesse meio, a aprendizagem ativa evidencia-se pela atitude e a intelectualidade do educando ao pensar, organizar, processar, elaborar, entender e divulgar, de maneira personalizada, o aprendizado norteado pela diversidade de abordagens, técnicas e estratégias.

\subsection{Metodologias ativas, ensino híbrido e tecnologias na EaD}

O conceito de metodologias ativas propõe uma transformação cultural no olhar sobre a Escola, da Básica a Superior, por todos que fazem parte do seu ciclo de desenvolvimento funcionários, gestores, docentes, estudantes e famílias. Alguns interpretam essas metodologias como a combinação de algumas técnicas e direcionamentos para que os alunos tenham interesse nas aulas, por exemplo: a aula invertida, a rotação por estações, a aprendizagem por projetos e todas empregadas de forma individual. Para outros, são estratégias que podem ser entendidas com maior complexidade e direcionadas para a 
participação dos estudantes de forma efetiva, tendo como objeto a integração de diferentes áreas do conhecimento e professores, como em projetos integradores (MORAN, 2018).

Um pequeno grupo de professores e gestores veem as metodologias ativas como parte de uma transformação com maior amplitude das escolas e instituições de Ensino Superior, de modo a promover uma reorganização em termos de currículos, passando a utilizar metodologias por projetos e reestruturar os ambientes, métodos avaliativos e também promover a participação mais ativa da comunidade (MORAN, 2018). Para esse autor, em relação à participação, os métodos são utilizados em associação a diferentes conceitos participativos. Para algumas IES ou escolas, a interação dos aprendizes fica limitada à execução das atividades propostas e, em outros casos, existem diferentes etapas de negociação, envolvimento e direcionamentos personalizados.

\subsubsection{Os modelos híbridos de ensino}

Segundo Valente (2014, p. 84), o Blended Learning ou Ensino Híbrido consiste em um programa de educação formal que mistura "momentos em que o aluno estuda os conteúdos e instruções usando recursos on-line, e outros em que o ensino ocorre em uma sala de aula, podendo interagir com outros alunos e com o professor", sendo que na parte que é realizada on-line, o estudante dispõe de meios que lhe possibilitam o controle de "quando, onde, como e com quem vai estudar". O referido autor vê como relevante para a aprendizagem dos alunos essa combinação do que ocorre presencialmente e on-line e afirma que "o uso da modalidade Blended Learning tem sido a tendência em muitos cursos de EaD".

Christensen, Horn e Staker (2013, p. 6) apresentam as quatro categorias nas quais se distribuem os modelos principais de Ensino Híbrido disponíveis no mercado. O modelo de Rotação, o modelo Flex, o modelo A La Carte e o modelo Virtual Enriquecido. A começar pelo modelo de Rotação, é aquele em que os alunos alternam entre as modalidades de ensino dentro de uma disciplina ou curso, com um roteiro específico ou com orientação do professor, sendo que pelo menos uma modalidade de ensino utilizada deverá ser on-line.

Conforme Christensen, Horn e Staker (2013, p. 27), outras atividades podem ser inseridas nessa modalidade, "[...] como as lições em grupos pequenos ou turmas completas, trabalhos em grupo, tutoria individual e trabalhos escritos". Para os autores, esse modelo possui quatro submodelos: Laboratório Rotacional, Sala de Aula Invertida, Rotação Individual e Rotação por Estações. Eles são especificados por Christensen, Horn e Staker (2013):

- Modelo de Rotação por Estações ou também conhecido por Rotação de Turmas ou Rotação em Classe é o modo em que os alunos se revezam no ambiente em que estão na aula;

- Modelo Laboratório Rotacional é aquele em que a rotação acontece entre um laboratório de aprendizado para o ensino on-line e a sala de aula;

- Modelo de Sala de Aula Invertida consiste naquele em que a rotação acontece entre a prática supervisionada pelo professor na forma presencial na instituição de ensino e a forma on-line, que se dá com a realização de atividades fora da escola, com a finalidade de aplicação dos conteúdos e lições estudados; 


\section{EmRede}

- Modelo de Rotação Individual diferencia-se dos demais modelos de Rotação, visto que cada aluno possui o seu roteiro individualizado e não tem necessidade de participar de todas as modalidades ou estações disponíveis.

Além do modelo de Rotação, Christensen, Horn e Staker (2013) apresentam outros. 0 modelo Flex tem por base o ensino on-line, mesmo que sejam realizadas atividades off-line em alguns momentos, tendo como finalidade a aprendizagem do aluno. Nesse formato, os estudantes se orientam por um roteiro flexível e adaptado de forma individual nas diferenciadas modalidades de ensino, e o professor responsável se encontra em uma mesma localidade.

Christensen, Horn e Staker ( 2013) ainda discorrem sobre o modelo A La Carte, que é de ensino híbrido, realizado totalmente on-line, de forma que os estudantes têm a possibilidade de fazer um ou mais cursos, tanto nas unidades físicas quanto externamente a essas unidades, a partir da mediação de um docente a distância, mas ao mesmo tempo, de forma concomitante, podem ter aulas em ambientes escolares tradicionais. Já o modelo Virtual Enriquecido é uma experiência vivenciada em escola integral, na qual, em cada componente curricular, os alunos distribuem seu tempo entre o aprendizado presencial e o aprendizado on-line, com acesso aos conteúdos e às lições.

\subsubsection{Tipos de metodologias ativas que utilizam tecnologias para EaD no Ensino Superior}

Dentre os diferenciados tipos de metodologias ativas, o mais referido na literatura é o chamado Problem Based Learning (PBL) em inglês, e Aprendizagem Baseada em Problemas (ABP) em português. No entanto, existem outras metodologias também consideradas ativas que são utilizadas nesse nível de ensino e serão apresentadas a seguir. Essa metodologia, embora tenha emergido nos anos 1960 na McMaster University no Canadá, tem elementos norteadores que foram trazidos muito antes por pesquisadores, como: Dewey, Piaget, Bruner, Rogers, Ausubel, Novak e Hanesian (FONSECA; MATTAR NETO, 2017).

Segundo a definição de Fonseca e Mattar Neto (2017), a PBL foi inspirada em princípios da escola ativa, um movimento educacional internacional que se iniciou no Brasil em meados de 1920, que prioriza o método científico com a integração dos conteúdos de diferentes áreas e ciclos de estudo e possibilita aos estudantes "aprender a aprender", com foco na resolução de problemas mediante a especificidade das possíveis profissões futuras. De acordo com os mesmos autores, a ABP tem como proposta trabalhar de forma transdisciplinar com base em diferentes temas, competências e problemas, de modo que os níveis de complexidade desses problemas sejam crescentes. Nessa metodologia, os alunos realizam atividades individuais e em grupos, os temas originam problemas que são discutidos em um grupo de tutores que apoia os estudos dos alunos.

A metodologia ativa Design Thinking (DT), conforme Rocha (2018), consiste em um método humanista de inovação e criatividade, centralizado na realização de trabalho colaborativo. Dessa forma, proporciona aos alunos a observação, criação e implementação de ideias e a proposição de soluções em contextos variados, de forma sistemática e 


\section{EmRede}

organizada. Essa metodologia é fundamentada na resolução de problemas sob diferentes perspectivas e fundamentada em três pilares: colaboração, empatia e experimentação, em busca de soluções com um tempo estipulado para experimentar as descobertas que vão surgindo com a pesquisa. Os integrantes de uma equipe, unidos colaborativamente, avaliam situações desafiadoras e acrescentam ideias, propõem reflexões, desafios e estabelecem conexão entre os membros das equipes mesmo que estejam dispersos no início (ARAUJO et al., 2014; PUGENS; HABOWSKI; CONTE, 2018).

A metodologia Flipped Classroom, ou Sala de Aula Invertida, torna possível a participação do estudante no processo pedagógico, pois privilegia práticas como leituras e pesquisas prévias aos encontros presenciais, com subsídios, como textos variados, vídeos e áudios, que podem possibilitar discussões em grupo, atividades em laboratórios, resolução de problemas e projetos, tudo com base na construção interativa em ambientes virtuais de aprendizagem (FONSECA; MOURA; FONSECA, 2015). Segundo Valente (2014), a Sala de Aula Invertida é um método que utiliza as TDICs e uma das possibilidades que mais se evidencia nos últimos tempos, podendo ser aplicada com eficácia, pois o docente disponibiliza com antecedência aos alunos os materiais que subsidiarão a aula, por exemplo, vídeos. Os estudantes assistem em casa por meio de alguma plataforma disponível em computador, celular ou tablet e, posteriormente, o assunto tratado no vídeo - ou em outro tipo de material disponibilizado - é discutido em sala de aula. Para Fonseca, Moura e Fonseca (2015), nessa metodologia, tudo é feito a partir de material didático, disponibilizado previamente em repositórios e pode promover o desenvolvimento da autonomia dos alunos, visto que a hibridez de estudos a distância, individual ou em grupos, torna-os aprendizes mais ativos. Para a utilização da Sala de Aula Invertida, deve haver necessariamente uma ressignificação da atuação do professor e dos estudantes, considerando a dinâmica, abarcando diferenciados espaços e tempos de interação e construção do conhecimento.

Outra metodologia ativa comumente aplicada na EaD é a Project-Based Learning (PBL), ou Aprendizagem Baseada em Projetos (ABP), que se caracteriza pela aprendizagem colaborativa dos alunos, com base no trabalho coletivo dos estudantes para investigar e responder determinado problema, questão complexa ou desafio. A ABP possibilita aos alunos realizarem uma mobilização de suas capacidades cognitivas e comportamentais, pois se baseia em fatores integrativos dos discentes, professores, método de ensino e ambiente educacional, o que pode auxiliar em mudanças promissoras no processo de ensino e de aprendizagem (QUEIROZ et al., 2016). Fonseca e Mattar Neto (2017) corroboram ao evidenciarem que a ABP pode possibilitar aos estudantes, por meio da resolução de problemas, construir novos conhecimentos e adquirir habilidades, isso envolve desafios reais e tarefas de investigação de questões complexas. Tudo feito desde o planejamento, passando pelo desenvolvimento do processo, até o momento avaliativo, proporcionando vivências que os preparará profissionalmente.

A metodologia Aprendizagem entre Pares ou Peer Instruction, para Rosa Junior (2015), consiste em um método de instrução que pode promover a interação dos alunos de forma mais ativa nos processos de aprendizagem, incluindo os professores e os tutores no caso da EaD. Fonseca e Mattar Neto (2017) caracterizam essa metodologia como aquela em que há a troca de conhecimentos e, por meio de atividades propostas, requer dos estudantes a realização de pesquisa prévia, interação e feedback constantes, fato que possibilita aos 
discentes atuarem como protagonistas da própria aprendizagem dos conceitos curriculares estudados.

A metodologia Aprendizagem Baseada em Equipes ou Team Based Learning (TBL), de acordo com Rosa Junior (2015), funda-se em uma estratégia de ensino que tem como objetivo a formação de grupos menores em classes numerosas, de maneira a se obter uma aprendizagem com mais significado. Nessa metodologia, o professor adota a postura de facilitador dos processos de ensinos e aprendizagem, oportunizando a todos a vivência e a autonomia para as ações. O TBL propicia aos alunos participarem ativamente, trocar conhecimentos e informações entre seus pares, privilegiando o senso de responsabilidade, 0 relacionamento interpessoal, a habilidade analítica e crítica, o trabalho em equipe, a resolução de problemas e tomadas de decisões com base nos em resultados a que chegarem.

A Aprendizagem Baseada em Games ou Gamificação é uma metodologia que permite aos tutores, monitores e professores dos cursos em EaD fomentar o engajamento e a motivação dos estudantes na realização de atividades nas plataformas digitais, devido ao acesso fácil e flexível às informações e serviços para os estudos. Nesse contexto, esse método oferece elementos de jogos, como: dinâmica, estética e mecânica, podendo promover experiências diversificadas e o desenvolvimento de competências por meio de estratégias inovadoras que auxiliam no processo de aprendizagem (CASTRO; GONÇALVES, 2018). Conforme Schlemmer (2014), a Gamificação consiste em adequar elementos presentes no design de jogo em propostas e desafios educacionais, em situações não consideradas como jogos, com a finalidade de tornar os processos de ensino e aprendizagem mais divertidos. Para o autor, a gamificação vem crescendo e tornando-se importante no meio educacional, que com o uso das diferentes mídias para a experimentação de jogos e narrativas interativas, tem proporcionado o desenvolvimento da autonomia e do pensamento crítico dos alunos. Além disso, permite a resolução de problemas com cooperação e colaboração, bem como a ampliação dos modos de ver o mundo de uma maneira mais divertida e essas diversas experiências vivenciadas contribuem para a construção do conhecimento.

\section{METODOLOGIA DO ESTUDO}

Este artigo traz resultados de um estudo bibliográfico, tanto para a parte teórica quanto para identificar estudos que tratam de metodologias ativas no Ensino Superior EaD. Assim, foram seguidas as três etapas colocadas por Sampaio e Mancini (2007): definir o objetivo do estudo, buscar na literatura estudos que tratam da temática em questão e selecionar aqueles passíveis de serem incluídos nas análises. A busca foi realizada no Google Acadêmico, considerando os descritores "metodologias ativas", "curso superior" e "educação a distância", que deveriam estar presentes em artigos publicados. Os resultados obtidos foram passíveis de filtros por meio de uma leitura dos títulos, resumos e, posteriormente, de todo o texto, considerando os que foram publicados de 2014 a 2019.

$\mathrm{Na}$ leitura dos artigos selecionados, privilegiou-se aqueles que apresentavam metodologias ativas utilizadas no Ensino Superior em EaD, Neste estudo bibliográfico, a abordagem foi qualitativa, envolvendo descrições e análises com base nos objetivos deste estudo (MARTINS; THEÓPHILO, 2007). 


\section{METODOLOGIAS ATIVAS NA EaD: TIPOS MAIS UTILIZADOS}

No Ensino Superior em EaD, foco deste estudo, o uso de metodologias ativas tem sido cada vez mais frequente, de acordo com Oliveira et al. (2015). Nessa perspectiva, estão apresentadas as metodologias ativas que estão sendo utilizadas em cursos em EaD, de acordo com os textos analisados. Entre as várias metodologias ativas, a Aprendizagem Baseada em Problemas (ABP) é frequentemente abordada na literatura, conforme já referido anteriormente. A título de exemplo, o estudo de Almeida, Silva e Bonamigo (2018) tomou para análise a contribuição da ABP na EaD com a finalidade de contribuir na área de Educação em saúde, por meio de uma revisão de literatura que considerou 12 artigos. Como resultados, apresentou que a $\mathrm{ABP}$ na área de saúde possibilita aos alunos o desenvolvimento de habilidades e competências de forma proativa, com o fortalecimento na construção do conhecimento; entretanto, mostra que há ainda a necessidade de pesquisas nessa direção que abordem a ABP e EaD nessa área.

Já o estudo de Garbin, Cavalcanti e Araújo (2017), por exemplo, abordou o Design Thinking como opção metodológica, visando práticas inovadoras que podem ser utilizadas em cursos superiores da EaD, com adoção de princípios da Aprendizagem Baseada em Problemas e por Projetos. Esses autores apresentam um relato do uso dessas metodologias na análise de um AVA de um curso semipresencial de Licenciatura em Ciências oferecido por duas universidades. Os resultados mostraram que os conteúdos apresentados nesse curso, por meio da referida metodologia, subsidiaram o desenvolvimento de projetos colaborativos em contextos reais, o que, segundo os autores, continua sendo adotado no contexto pesquisado, ou seja, passaram a integrar os currículos e as metodologias ativas utilizadas nas práticas pedagógicas.

Outra metodologia ativa presente na literatura estudada é a Flipped Classroom, ou Sala de Aula Invertida. A título de exemplo, o estudo de Nóbrega, David e Silva (2018) teve por objetivo investigar fatores intervenientes da aprendizagem, a partir da aplicação de tal metodologia em um curso de graduação de uma IES. Os dados admitidos para análise foram: experiências com EaD, relação entre prática e teoria, material da aula, recursos didáticos, trabalhos escritos apresentados pelos alunos e verificação sobre outros cursos em EaD. Os resultados revelaram que a Sala de Aula Invertida é um método que possibilitou ampliar a participação e o interesse dos alunos na realização das atividades, tal fato pode influenciar beneficamente no aprendizado, além de proporcionar a autonomia dos alunos nas aulas.

A Aprendizagem Baseada em Projetos é outro exemplo comumente utilizado na EaD. 0 estudo de Gallo (2019) mostrou que essa metodologia pode auxiliar as IES a enfrentar o desafio de manter os alunos de cursos de bacharelado da modalidade a distância interessados e comprometidos, agindo de forma ativa no ambiente virtual, interagindo com os colegas e tutores. Para esse autor, a Aprendizagem Baseada em Projetos vem apresentando um maior engajamento entre os alunos na Educação Superior. Trata-se de uma combinação de metodologias que propicia aos alunos a realização de um projeto anual, o qual lhes possibilita cercar-se de experiências acadêmicas e dos conteúdos, compondo uma narrativa em forma de vídeo, texto, hipertexto e streaming. Dessa forma, o aluno é quem define a sua forma de estudar, como também os recursos e objetos de estudos, o que permite ao estudante fazer uma interseção entre as disciplinas e o desenvolvimento do projeto que 
abrange problemas reais e, ao final, os alunos podem apresentar um produto palpável. 0 resultado indicou que houve um maior comprometimento dos discentes com o curso, pois conseguiram fazer uma conexão entre a vida pessoal e profissional por meio dos conceitos que estavam aprendendo, além de levarem as experiências das aprendizagens adquiridas para os ambientes externos.

Outro modelo de metodologia ativa utilizada no Ensino Superior EaD é a Aprendizagem Baseada em Games ou Gamificação. A título de exemplo, o estudo de Santos, Almeida e Cruz (2018) teve por objetivo analisar a reestruturação metodológica de uma disciplina da graduação Hermenêutica Jurídica na modalidade $\mathrm{EaD}$, oferecida na Universidade de Fortaleza (UNIFOR). Esse estudo tratou de como pode ocorrer a reestruturação do projeto institucional dessa disciplina, em termos de inovação das metodologias de ensino empregadas. Os resultados apontaram que, com as inovações metodológicas, o processo de ensino e aprendizagem passa por mudanças, atendendo à necessidade de inserir novos tipos de metodologias e tecnologias, sobretudo na modalidade EaD. Também evidenciaram que a Gamificação visa novas maneiras e desafios com relação aos processos de ensino e aprendizagem, tornando os alunos mais participativos em relação ao próprio aprendizado, o que pode acrescentar um valor pedagógico ao material didático inovador.

A Aprendizagem entre Pares, ou Peer Instruction, é mais uma das metodologias adotadas no Ensino Superior EaD. Para exemplificá-la, pode-se citar o estudo de Amaro Silva (2017), que a utilizou em um AVA, e que contou com os benefícios da ferramenta Laboratório de Avaliação - Workshop Moodle. Essa pesquisa qualitativa e exploratória foi aplicada em alunos de quatro disciplinas, três em formato presencial e uma em EaD, do primeiro semestre de 2017, dos cursos de Licenciatura e Bacharelado em Educação Física oferecidos pela Universidade de Brasília. Esse Laboratório de Avaliação recebe arquivos para o processo avaliativo e depois atribui esses arquivos à avaliação dos colegas, em mais de uma atividade, tratando-se de uma ferramenta versátil que permite diferentes formatos digitais - doc, pdf, planilhas, vídeos - e que possibilita a edição do texto no próprio Moodle e, para o docente, disponibiliza um formulário direcionado de avaliação. Nas quatro disciplinas, os alunos fizeram atividade de criação textual relacionada aos objetivos da unidade didática e, além do direcionamento conceitual, privilegiou-se a divulgação da experiência da prática avaliativa entre seus pares. Os resultados mostraram que o Laboratório de Avaliação facilitou a avaliação de mais de uma atividade dos alunos, que também podiam indicar a autoavaliação das atividades. Então, quando feita a configuração dessa ferramenta pelo docente, inscrições e revisões anônimas foram possibilitadas.

Pode-se citar também a Aprendizagem Baseada em Equipes ou Team Based Learning (TBL). Como exemplo, toma-se o estudo de Watté et al. (2018) que teve por objetivo implementar uma metodologia Team Based Learning (TBL) no âmbito de estratégia de Blended Learning em um treinamento para desenvolvimento da disciplina de Empreendedorismo no formato de Hibridismo. Para tanto, os pesquisadores desenvolveram o plano de curso e a matriz instrucional dessa disciplina, bem como implementaram o curso em um ambiente virtual. Os resultados indicaram que essa metodologia proporcionou aos estudantes um ganho na dinâmica de seus estudos por ser um novo método de aprendizagem atrativo, e aos docentes, foi oportunizada a inovação dos métodos de trabalho e a evolução pedagógica profissional. Em relação à elaboração do plano de curso, este foi construído a 
partir de buscas obtidas com ferramentas Google e feita uma sistematização e adequação aos objetivos dessa IES. A estrutura da matriz instrucional foi desenvolvida com base na proposta da metodologia TBL, conforme Michaelsen e Sweet (2008), com acréscimos de elementos da modalidade EaD, fundamentada nas percepções e opiniões individuais dos membros do grupo. Desse modo, evidenciaram que tanto os docentes quanto os discentes acessam simultaneamente no Moodle os resultados e as devolutivas para prosseguirem as ações educativas que norteiam os processos de ensino e de aprendizagem.

A literatura pertinente ao uso de metodologias ativas aplicadas à educação no Ensino Superior na modalidade EaD traz, além da definição e compreensão sobre essa temática, alguns pontos relevantes, como aquelas metodologias mais comumente utilizadas em cursos de graduação a distância e sua aplicabilidade em variadas áreas. Esses estudos mostram que utilizar essas metodologias contribui para uma aprendizagem ativa, em virtude da participação e envolvimento dos alunos nas aulas, o que pode possibilitar, além da compreensão dos conceitos estudados, o desenvolvimento de valores formativos, como: a ética, a habilidade de crítica e reflexão sobre diferenciados assuntos em amplo espectro, a participação e interação em trabalhos em equipes, com o desenvolvimento da autonomia e possibilidade de protagonismo dos estudantes no processo educativo.

As oportunidades de uso didático de metodologias ativas na EaD são várias, tendo em vista que essas metodologias, se bem estruturadas no processo de intermediar e conduzir a aprendizagem dos alunos, podem ocasionar a assimilação de novos conhecimentos com o desenvolvimento de habilidades, como a independência, a organização, a autocrítica, o autoconhecimento, o poder de análise, a comunicação e a argumentação. Considerando que essa modalidade de ensino se dá em maior parte na forma on-line, a comunicação digital acaba sendo mais acessível, levando em conta o dinamismo em relação ao espaço e tempo, facilitando o estabelecimento de novos contatos com indivíduos que possuem o mesmo objetivo, no entanto, fisicamente separados, o que acaba dando ao indivíduo maior liberdade para se expor e se posicionar em relação aos assuntos em pauta, conforme elucida Valente(2014).

Outro aspecto que merece atenção é a formação dos docentes para acompanhar as transformações ocorridas na EaD com o advento das tecnologias digitais, visto que a utilização de metodologias ativas nessa modalidade de ensino exige dos docentes, além do conhecimento dos conteúdos estudados, o conhecimento pedagógico para ministrá-los em diferentes ambientes virtuais. Diferenciados também são os suportes em que se encontram os materiais, o que exige dos docentes competências para gerir as diferenciadas ferramentas tecnológicas utilizadas na EaD. Nessa perspectiva, observou-se a importância de as instituições de ensino oferecerem cursos de formação continuada sobre a utilização de metodologias ativas subsidiadas por tecnologias digitais e de acompanharem os impactos de sua utilização no trabalho docente.

Ainda pode-se citar a necessidade de reestruturação, reorganização e adequação dos currículos dos cursos superiores em EaD, já que na maioria dos cursos há uma sobrecarga de 


\section{EmRede}

conteúdos programáticos que devem ser estudados em uma carga horária apertada, o que acaba por inviabilizar a utilização das metodologias ativas que demandam um maior tempo, pois priorizam a resolução de problemas da realidade com reflexões, discussões em grupo para a apresentação de resultados e posterior aplicação na tomada de decisões. Isso corrobora o que mencionam Moran (2018) e Masetto (2018) acerca das metodologias ativas que vêm valorizar o protagonismo dos alunos, com envolvimento nas atividades de forma participativa, autônoma e reflexiva em todo o processo.

Os estudos mostram que as metodologias ativas subsidiadas por tecnologias digitais são inovadoras e podem possibilitar diferentes oportunidades, quando aplicadas em cursos de graduação em EaD. Para estudos futuros, pode-se analisar essa temática especificamente no âmbito da pós-graduação, que também integra o Ensino Superior e não foi abordada nesse artigo. Isso, porque, essas metodologias evidenciam-se como promissoras no sentido de propiciar que os estudantes e docentes acompanhem as transformações colocadas pela evolução das TDICs em todos os setores da sociedade. Assim, as instituições de Ensino Superior que oferecem cursos na modalidade EaD podem usufruir dessas metodologias no que diz respeito à inovação das práticas metodológicas de ensino, contribuindo para uma educação que não pode se ausentar de promover mudanças no fazer pedagógico, a fim de que os alunos possam ter uma formação na qual desenvolvam habilidades e competências em prol de uma atuação profissional e social voltada ao exercício da cidadania.

\section{REFERÊNCIAS}

ALMEIDA, S. G.; TELES, C. C. Sala de aula invertida: relato de experiência em educação a distância e presencial com uso de ambiente virtual de aprendizagem na graduação.

EmRede-Revista de Educação a Distância, v. 5, n. 3, p. 599-625, 2018. Disponível em: https://www.aunirede.org.br/revista/index.php/emrede/article/view/360/405. Acesso em: 02 maio 2020.

ALMEIDA, V. O.; SILVA, H. T. H.; BONAMIGO, A. W. Aprendizagem baseada em problemas na educação a distância e as influências para educação em saúde: uma revisão integrativa. Revista Brasileira de Aprendizagem Aberta e a Distância, São Paulo, v. 17, n. 1, p. 1-22, 2018. Disponível em: http://seer.abed.net.br/index.php/RBAAD/article/view/24/250. Acesso em: 02 maio 2020.

ALONSO, K. M.; SILVA, D. G. A educação a distância e a formação on-line: o cenário das pesquisas, metodologias e tendências. Educação \& Sociedade, Campinas, v. 39, n. 143, p. 499-514, 2018. Disponível em: https://www.scielo.br/pdf/es/v39n143/1678-4626-es-39-143499.pdf. Acesso em: 13 abr. 2020.

AMARO, R.; SILVA, W. B. Avaliação por pares e metodologias ativas na formação de professores. In: $23^{\circ}$ CIAED CONGRESSO INTERNACIONAL ABED DE EDUCAÇÃO A DISTÂNCIA, 2017, Foz de Iguaçu. Anais [...]. Foz de Iguaçu: Associação Brasileira de Educação a Distância, 2017. Disponível em: http://www.abed.org.br/congresso2017/trabalhos/pdf/247.pdf. Acesso em: 06 jun. 2020. 
ARAUJO, U. F. et al. A reorganização de tempos, espaços e relações na escola com o uso de metodologias ativas de aprendizagem e ferramentas colaborativas. ETD - Educação

Temática Digital, Campinas, v. 16, n. 1, p. 84-99, 2014. Disponível em: https://periodicos.sbu.unicamp.br/ojs/index.php/etd/article/view/1331/pdf. Acesso em: 03 maio 2020.

BACICH, L.; MORAN, J. Aprender e ensinar com foco na educação híbrida. Revista Pátio, v. 17, n. 25, p. 45-47, 2015. Disponível em:

https://www.academia.edu/19537087/Aprender e ensinar com foco na Educa\%C3\%A7\% C3\%A30_H\%C3\%ADbrida. Acesso em: 14 mar. 2020.

BRASIL. Decreto $\mathbf{n}^{\circ}$ 9.057, de 25 de maio de 2017. Regulamenta o art. 80 da Lei ${ }^{\circ}$ 9.394, de 20 de dezembro de 1996, que estabelece as diretrizes e bases da educação nacional. Brasília, DF: Presidência da República, 2017. Disponível em:

http://www.planalto.gov.br/ccivil_03/_ato2015-2018/2017/decreto/d9057.htm. Acesso em: 07 abr. 2020.

BRASIL. Lei $\mathbf{n}^{\circ}$ 9.394, de 20 de dezembro de 1996. Estabelece as diretrizes e bases da educação nacional. Brasília, DF: Presidência da República, 1996. Disponível em: http://www.planalto.gov.br/ccivil 03/LEIS/19394.htm. Acesso em: 07 abr. 2020.

BRASIL. Ministério da Educação. Portaria n 2.117, de 06 de dezembro de 2019. Dispõe sobre a oferta de carga horária na modalidade de Ensino a Distância - EaD em cursos de graduação presenciais ofertados por Instituições de Educação Superior - IES pertencentes ao Sistema Federal de Ensino. Brasília, DF: Ministério da Educação, 2019. Disponível em: http://www.in.gov.br/en/web/dou/-/portaria-n-2.117-de-6-de-dezembro-de-2019232670913. Acesso em: 12 abr. 2020.

BRASIL. Ministério da Educação. Portaria $\mathbf{n}^{0}$ 2.253, de 18 de outubro de 2001. Dispõe sobre a introdução nas instituições de ensino superior do sistema federal de ensino, na organização pedagógica e curricular de seus cursos superiores reconhecidos, a oferta de disciplinas que, em seu todo ou em parte, utilizem método não presencial, com base no art. 81 da Lei n. 9394, de 1996. Brasília, DF: Ministério da Educação, 2001. Disponível em: https://www2.camara.leg.br/legin/marg/portar/2001/portaria-2253-18-outubro-2001412758-norma-me.html. Acesso em: 13 abr. 2020.

BRASIL. Ministério da Educação. Portaria $n^{\circ}$ 4059, de 10 de dezembro de 2004. As instituições de ensino superior poderão introduzir, na organização pedagógica e curricular de seus cursos superiores reconhecidos, a oferta de disciplinas integrantes do currículo que utilizem modalidade semipresencial, com base no art. 81 da Lei n. 9.394, de 1.996, e no disposto nesta Portaria. Brasília, DF: Ministério da Educação, 2004. Disponível: http://portal.mec.gov.br/sesu/arquivos/pdf/nova/acs_portaria4059.pdf. Acesso em: 09 abr. 2020.

BRASIL. Ministério da Educação. Secretaria de Educação a Distância. Referenciais de Qualidade para Educação Superior a Distância. Brasília, 2007. Disponível em: http://portal.mec.gov.br/seed/arquivos/pdf/legislacao/refead1.pdf. Acesso em: 09 abr. 2020.

CAMARGO, R. Z.; LIMA, M. C.; TORINI, D. M. Educação, mídia e internet: desafios e possibilidades a partir do conceito de letramento digital. Revista Brasileira de Psicodrama, 
v. 27, n. 1, p. 106-116, 2019. Disponível em:

http://pepsic.bvsalud.org/pdf/psicodrama/v27n1/11.pdf Acesso em: 09 abr. 2020.

CASTRO, Talita Candida; GONÇALVES, Luciana Schleder. Uso de gamificação para o ensino de informática em enfermagem. Revista Brasileira de Enfermagem, Brasília, v. 71, n. 3, p. 1101-1108, 2018. Disponível em: https://www.scielo.br/pdf/reben/v71n3/pt 0034-7167reben-71-03-1038.pdf. Acesso em: 25 maio 2020.

CHRISTENSEN, C. M.; HORN, M. B.; STAKER, H. Ensino híbrido: uma inovação disruptiva? Uma introdução à teoria dos híbridos. Tradução: Fundação Lemann, Instituto Península. 2013. Disponível em: https://s3.amazonaws.com/porvir/wp-content/uploads/2014/08/PT IsK-12-blended-learning-disruptive-Final.pdf. Acesso em: 02 maio 2020.

COSTA, J. R. de M. 0 processo de institucionalização da educação a distância no Brasil. 2012. 167 f. Tese (Doutorado em Educação) - Universidade Federal do Rio Grande do Sul, Porto Alegre, 2012. Disponível em: https://www.lume.ufrgs.br/handle/10183/49813 Acesso em: 02 maio 2020.

DONATO, S. P.; GHILARDI, R. Aprendizagem na modalidade semipresencial: representações sociais de estudantes de licenciaturas. In: CONGRESSO INTERNACIONAL DE EDUCAÇÃO E TECNOLOGIA/ENCONTRO DE PESQUISADORES EM EDUCAÇÃO A DISTÂNCIA, 2018, São Carlos. Anais [.... . São Carlos: CIET/EnPED, 2018. Disponível em: https://cietenped.ufscar.br/submissao/index.php/2018/article/view/531/59. Acesso em: 09 abr. 2020.

FERRARINI, R.; SAHEB, D.; TORRES, P. L. Metodologias ativas e tecnologias digitais: aproximações e distinções. Revista Educação em Questão, Natal, v. 57, n. 52, p. 1-30, 2019. Disponível em: https://periodicos.ufrn.br/educacaoemquestao/article/view/15762/11342. Acesso em: 03 abr. 2020.

FONSECA, J. J. S.; MOURA, A. A.; FONSECA, S. H. P. A aprendizagem invertida em educação a distância. In: $21^{\circ}$ CIAED CONGRESSO INTERNACIONAL ABED DE EDUCAÇÃO A DISTÂNCIA, 2015, Bento Gonçalves. Anais [...]. Bento Gonçalves: Associação Brasileira de Educação a Distância, 2015. p. 1-10. Disponível em:

http://www.abed.org.br/congresso2015/anais/pdf/BD_86.pdf. Acesso em: 03 maio 2020.

FONSECA, S. M.; MATTAR NETO, J. A. Metodologias ativas aplicadas à educação a distância: revisão de literatura. Revista EDaPECI: Educação a Distância e Práticas Educativas Comunicacionais e Interculturais, São Cristóvão (SE), v. 17, n. 2, p. 185-197, 2017. Disponível em: https://seer.ufs.br/index.php/edapeci/article/view/6509/pdf. Acesso em: 02 maio 2020.

GALLO, P. Aprendizagem baseada em projetos e narrativa transmídia: abordagens para o engajamento dos alunos no bacharelado a distância. 2019. Disponível: http://www.abed.org.br/congresso2019/anais/trabalhos/31220.pdf. Acesso em: 24 maio 2020.

GARBIN, M. C.; CAVALCANTI, C. C.; ARAÚJO, U. F. Metodologias ativas de aprendizagem na formação semipresencial de professores: articulando teoria e prática. International Studies on Law and Education, São Paulo, v. 27, p. 13-28, 2017. Disponível em: https://repositorio.usp.br/item/002805436. Acesso em: 02 maio 2020. 
GOMES, L. F. EAD no Brasil: perspectivas e desafios. Avaliação: Revista da Avaliação da Educação Superior, Campinas, v. 18, n. 1, p. 13-22, 2013. Disponível em: https://www.scielo.br/scielo.php?script=sci_arttext\&pid=S1414$40772013000100002 \& \operatorname{lng}=e n \& n r m=i s o$ Acesso em: 02 maio 2020.

LÁZARO, A. C.; SATO, M. A. V.; TEZANI, T. C. R. Metodologias ativas no ensino superior: o papel do docente no ensino presencial. In: CONGRESSO INTERNACIONAL DE EDUCAÇÃO E TECNOLOGIA/ENCONTRO DE PESQUISADORES EM EDUCAÇÃO A DISTÂNCIA, 2018, São Carlos. Anais [....]. São Carlos: CIET/EnPED, 2018. Disponível em: https://cietenped.ufscar.br/submissao/index.php/2018/article/view/234/282. Acesso em: 14 mar. 2020.

MAIA, C.; MATAR, J. ABC da EaD: a educação a distância hoje. São Paulo: Pearson Prentice Hall, 2007.

MARTINS, G. A.; THEÓPHILO, C. R. Metodologia da investigação científica para ciências sociais aplicadas. São Paulo: Atlas, 2007.

MASETTO, M. T. Metodologias ativas no ensino superior: para além da sua aplicação, quando fazem a diferença na formação de profissionais? Revista e-Curriculum, São Paulo, v. 16, n. 3, p. 650-667, 2018. Disponível em: https://revistas.pucsp.br/curriculum/article/view/37099/26724. Acesso em: 09 abr. 2020.

MICHAELSEN, L. K.; SWEET, M. The essential elements of team-based learning. New directions for teaching and learning, n. 316, p. 7-27, 2008. Disponível em: https://teamlead.duke-nus.edu.sg/vapfiles_ocs/2011/edu/Essential_Elements.pdf. Acesso em: 02 maio 2020.

MORAN, J. Metodologias ativas para uma aprendizagem mais profunda. In: $\mathrm{BACICH}, \mathrm{L}$.; MORAN, J. Metodologias ativas para uma educação inovadora: uma abordagem teóricoprática. Porto Alegre: Penso, 2018.

MORAN, J. Mudando a educação com metodologias ativas. In: SOUZA, C. A.; MORALES, O. E. T. (org.). Convergências midiáticas, educação e cidadania: aproximações jovens. Ponta Grossa: UEPG, 2015. Disponível em: http://www2.eca.usp.br/moran/wpcontent/uploads/2013/12/mudando_moran.pdf. Acesso em: 12 abr. 2020.

NÓBREGA, P. P.; DAVID, P. B.; SILVA, A. S. R. Sala de aula invertida e fatores intervenientes da aprendizagem: experiência em uma instituição federal de ensino superior com uma turma de alunos de graduação. Revista Científica de Educação a Distância, Rio de Janeiro, v. 10, n. 18, 2018. Disponível em:

https://periodicos.unimesvirtual.com.br/index.php/paideia/article/view/853/838. Acesso em: 02 maio 2020.

NONATO, E. R. S.; SALES, M. V. S.; SARLY, C. R. Educação a distância, hibridismo e metodologias ativas: fundamentos conceituais para uma proposta de modelo pedagógico na oferta das disciplinas semipresenciais dos cursos presenciais de graduação da UNEB.

EmRede-Revista de Educação a Distância, v. 6, n. 2, p. 161-171, 2019. Disponível em: 
https://www.aunirede.org.br/revista/index.php/emrede/article/view/489. Acesso em: 02 maio 2020.

OLIVEIRA, L. R. et al. Metodologias ativas de ensino-aprendizagem e suas convergências com as Tecnologias Digitais de Informação e Comunicação. In: VÁZQUEZ, J. Z.; JIMÉNEZ, R. S.; MORENO, M. A. G. (coord.). (org.). Desafios e oportunidades para a formação e atuação do profissional da informação na era digital. Madrid: Universidad Complutense de Madrid, 2015. Disponível em:

http://www.repositorio.ufc.br/bitstream/riufc/18159/1/2015 capliv Iroliveiralecavalcanteas rsilvarmrolim.pdf. Acesso em: 23 abr. 2020.

OLIVEIRA, P. C.; CUNHA, C. J. C. A.; NAKAYAMA, M. K. Learning management systems (LMS) and e-learning management: an integrative review and research agenda. JISTEM-Journal of Information Systems and Technology Management, v. 13, n. 2, p. 157-180, 2016.

Disponível em: https://www.scielo.br/scielo.php?pid=S1807-

17752016000200157\&script=sci_arttext. Acesso em: 23 abr. 2020.

PUGENS, N. B.; HABOWSKI, A. C.; CONTE, E. Reflexões sobre o design thinking na educação a distância: produção de novos sentidos. In: CONGRESSO INTERNACIONAL DE EDUCAÇÃO E TECNOLOGIA/ENCONTRO DE PESQUISADORES EM EDUCAÇÃO A DISTÂNCIA, 2018, São Carlos. Anais [.... . São Carlos: CIET/EnPED, 2018. Disponível em: https://cietenped.ufscar.br/submissao/index.php/2018/article/view/519/564. Acesso em: 13 abr. 2020.

QUEIROZ, J. R. C. et al. Aprendizagem por projeto e inovação tecnológica: união por competências. Revista da ABENO, v. 16, n. 2, p. 2-6, 2016. Disponível em: https://revabeno.emnuvens.com.br/revabeno/article/view/243/213. Acesso em: 13 abr. 2020.

ROCHA, J. Design thinking na formação de professores: novos olhares para os desafios da educação. In: BACICH, L.; MORAN, J. Metodologias ativas para uma educação inovadora. Porto Alegre: Penso, 2018.

ROSA JUNIOR, L. C. Metodologias ativas de aprendizagem para a educação a distância: uma análise didática para dinamizar sua aplicabilidade. 2015. 100 f. Dissertação (Mestrado em Tecnologia da Inteligência e Design Digital) - Pontifícia Universidade Católica de São Paulo, São Paulo, 2015. Disponível em: https://tede2.pucsp.br/bitstream/handle/18201/1/Luiz\%20Carlos\%20Rosa\%20 Junior.pdf. Acesso em: 30 maio 2020.

SAMPAIO, R. F.; MANCINI, M. C. Estudos de revisão sistemática: um guia para síntese criteriosa da evidência científica. Revista Brasileira de Fisioterapia, São Carlos, v. 11, n. 1, p. 83-89, 2007. Disponível em: https://www.scielo.br/pdf/rbfis/v11n1/12.pdf. Acesso em: 20 mai. 2017.

SANTO, E. E.; COLVARA, J. S. Metodologias ativas no ensino superior: o hibridismo da sala de aula invertida. Revista Brasileira de Aprendizagem Aberta e a Distância, São Paulo, v. 18, n. 1, p. 1-19, 2019. Disponível em: http://seer.abed.net.br/index.php/RBAAD/article/view/325/306. Acesso em: 05 abr. 2020. 
SANTOS, B. B.; ALMEIDA, A. C. A; CRUZ, A. N. Gamificação aplicada à educação: um relato de experiência na disciplina hermenêutica jurídica. In: $24^{\circ} \mathrm{CIAED}$ CONGRESSO INTERNACIONAL ABED DE EDUCAÇÃO A DISTÂNCIA, 2018, Florianópolis. Anais [...]. Florianópolis: Associação Brasileira de Educação a Distância, 2018. Disponível em:

http://www.abed.org.br/congresso2018/anais/trabalhos/6255.pdf. Acesso em: 25 maio 2020.

SCHLEMMER, E. Gamificação em espaços de convivência híbridos e multimodais: design e cognição em discussão. Revista da FAEEBA - Educação e Contemporaneidade, Salvador, v. 23, n. 42, p. 73-89, 2014. Disponível em:

https://www.revistas.uneb.br/index.php/faeeba/article/view/1029/709. Acesso em: 25 maio 2020.

SILVA, C. P.; LIMA, T. G. Importância das tecnologias de comunicação e informação (TICS) na educação técnica profissional e no ensino superior. In: JUNIOR, J. M. A.; SOUZA, L. P.; SILVA, N. L. C. Metodologias ativas: práticas pedagógicas na contemporaneidade. Campo Grande: Inovar, 2019. Disponível em: https://editorainovar.com.br/ files/2000001364505c4505e/Livro\%20Metodologias\%20ativas\%20pr\%C3\%A1ticas\%20pedag\%C3\%B3gicas \%20na\%20contemporaneidade-0.pdf. Acesso em: 08 abr. 2020.

SOUZA, C. A.; MORALES, O. E. T. (org.). Convergências midiáticas, educação e cidadania: aproximações jovens. Ponta Grossa: UEPG, 2015. Disponível em: http://www2.eca.usp.br/moran/wp-content/uploads/2013/12/mudando_moran.pdf. Acesso em: 12 abr. 2020.

VALENTE, J. A. Blended learning e as mudanças no ensino superior: a proposta da sala de aula invertida. Educar em Revista, Curitiba, n. 4, p. 79-97, 2014. Disponível em: https://www.scielo.br/pdf/er/nspe4/0101-4358-er-esp-04-00079.pdf. Acesso em: 25 fev. 2020.

VALENTE, J. A. Tecnologias e educação a distância no ensino superior: uso de metodologias ativas na graduação. Trabalho \& Educação, Belo Horizonte, v. 28, n. 1, p. 97-113, 2019. Disponível em: https://periodicos.ufmg.br/index.php/trabedu/article/view/9871/9929. Acesso em: 02 maio 2020.

WATTÉ, B. H. et al. Implementação da metodologia Team Based Learning (TBL) em uma estratégia de Blended Learning, no desenvolvimento da disciplina de Empreendedorismo. In: SPANHOL, F. J.; FARIAS, G. F.; SOUZA, M. V. EAD, PBL e o desafio da educação em rede: metodologias ativas e outras práticas na formação do educador coinvestigador. São Paulo: Blucher, 2018. Disponível em: https://openaccess.blucher.com.br/article-details/03-21381. Acesso em: 06 jun. 2020.

YAEGASHI, S. F. R. et al. Novas tecnologias digitais: reflexões sobre mediação, aprendizagem e desenvolvimento. Curitiba: CRV, 2017. p. 23-35. 